\title{
Unlike American Robins (Turdus migratorius), European Starlings (Sturnus vulgaris) do not display roost-time restlessness
}

\author{
LEONARD A. EISERER \\ Elizabethtown College, Elizabethtown, Pennsylvania \\ and \\ ROGER K. R. THOMPSON \\ Franklin \& Marshall College, Lancaster, Pennsylvania
}

\begin{abstract}
The daily perch-hop activity of six captive European Starlings (Sturnus vulgaris) was observed under natural lighting over 12 months. Moderately high levels of early morning activity gradually declined throughout the day. Unlike robins (Turdus migratorius), however, the starlings showed no evidence of the brief burst of activity at dusk called roost-time restlessness (Eiserer, 1979). The present data support the hypothesis that roost-time restlessness depends upon the conjunction of territorial and roosting behaviors, which is the case for robins but not for starlings.
\end{abstract}

Observers have long noted that American Robins (Turdus migratorius) are characteristically restless around dusk before their daily flight to a communal roost (e.g., Brewster, 1890). This phenomenon is reflected also in the daily activity pattern of captive robins under conditions of natural illumination (Eiserer, 1979, 1981). In particular, moderately high activity levels in the early morning gradually decline as the day progresses, but a brief period of high activity invariably occurs at dusk, before the birds settle down for the night (Eiserer, 1979; Palmer, 1970). Several lines of evidence suggest that the activity peak at dusk reflects the robin's tendency to fly to a communal roost site each evening (Eiserer, 1980a, 1980b, $1980 \mathrm{c}, 1981$ ). As such, this roost-time restlessness seems analogous to the seasonal migratory restlessness that many species of birds display in captivity (Eyster, 1954; Smith, Brown, \& Mewaldt, 1969).

One puzzling feature of roost-time restlessness is its temporal asymmetry. If the activity peak at dusk reflects a readiness to fly to the roost site, why then is there no corresponding peak of activity at dawn when the birds would normally be leaving their roosts? One possibility is that a territorial species like the robin requires extreme physiological readiness to induce it to abandon its daytime territory at dusk, but not to return to it from the roost on the following morning. If this explanation is correct, then bird species that are not territorial, but that roost communally, should not show roost-time restlessness when kept in captivity.

In the present study, we tested the hypothesis that roosttime restlessness depends upon the conjunction of ter-

Reprint requests may be sent to $\mathrm{L}$. A. Eiserer, Department of Psychology, Elizabethtown College, Elizabethtown, PA 17022. ritorial and roosting behaviors by monitoring for 1 year the daily activity patterns of captive European Starlings (Sturnus vulgaris). As described by Feare (1984), the starling, like the robin, is a migratory species that roosts communally at night throughout the year, though most noticeably in the winter. Starlings, however, are not territorial in the conventional sense described for robins (Davis, 1959; Young, 1951).

\section{METHOD}

Subjects

Six starlings (Sturnus vulgaris) of undetermined sex served as subjects. The birds were taken from the wild as adults, and had been housed together in an indoor aviary $(1.84 \times 1 \times 1.63 \mathrm{~m})$ for about 6 months before the present study commenced. During the period reported here, the starlings were individually housed in metal wire cages $(35 \times 50 \times 38 \mathrm{~cm}$ ) placed in a $3.4 \times 7.4 \mathrm{~m}$ room illuminated only by sunlight entering four windows. Room temperature was maintained at about $21^{\circ} \mathrm{C}$.

Each cage permitted continuous access to both food (Purina Game Bird Maintenance) and water, and was equipped with two parallel perches that lay some $20 \mathrm{~cm}$ apart. The cages were separated by cardboard dividers, so that the starlings were visually isolated from one another, but could hear each other's vocalizations.

\section{Procedure}

The subjects were observed from dawn to dusk for 2 days during each of 12 consecutive months. Specifically, the number of locomotor movements generated by each bird was recorded for the initial 1-min period of every 10-min block throughout the day. The observation days always fell near the middle of the month, and in all cases afforded essentially cloudless weather. Times of sunrise and sunset for the observation days were determined from the tables provided by Bishop (1985).

Throughout the observation period, the investigator sat quietly in a chair about $3 \mathrm{~m}$ in front of the cages. Previous research with robins has demonstrated that the visible presence of a quiet observer 
does not change the overall pattern of circadian activity in that species (Eiserer, 1981).

In the type of cage used here, the dominant locomotor activity of captive robins consists of movement from one perch to another, but starlings are a more agile species. To record only perch hops in starlings would have led to gross understatements of locomotor activity, because the birds also hopped between a perch and the side of the cage or the cage floor, between a food cup and the side of the cage, between one side of the cage and another, and so forth. Thus, the starlings' behavior was quantified by counting the number of discrete locomotor movements, which consisted of any of the above actions.

\section{RESULTS}

Figure 1 shows for each month the group mean number of locomotor responses across time of day. These data reveal that the starlings generated essentially the same basic activity pattern throughout the year. During all 12 months there was a period of morning activity, which declined gradually as the day progressed. Most important for our present purposes was the finding that the starlings, unlike robins (see Figures 1 and 2), did not generate a marked activity peak at dusk during any month
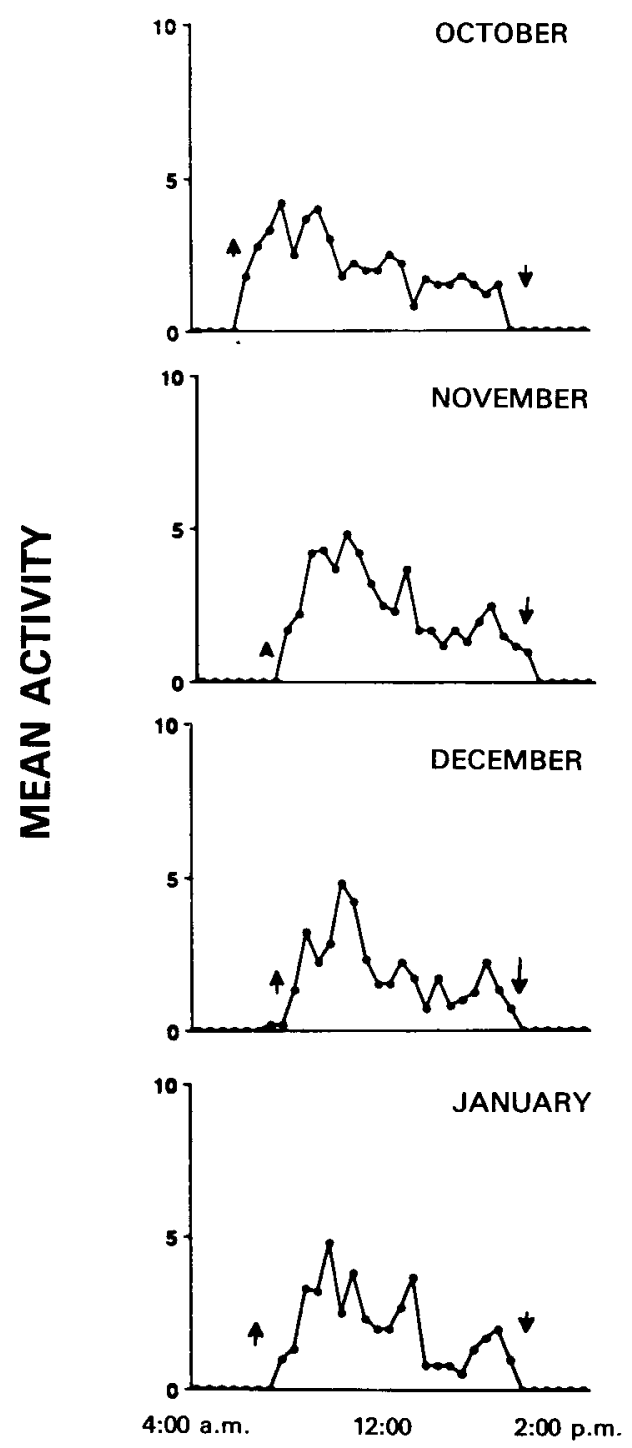
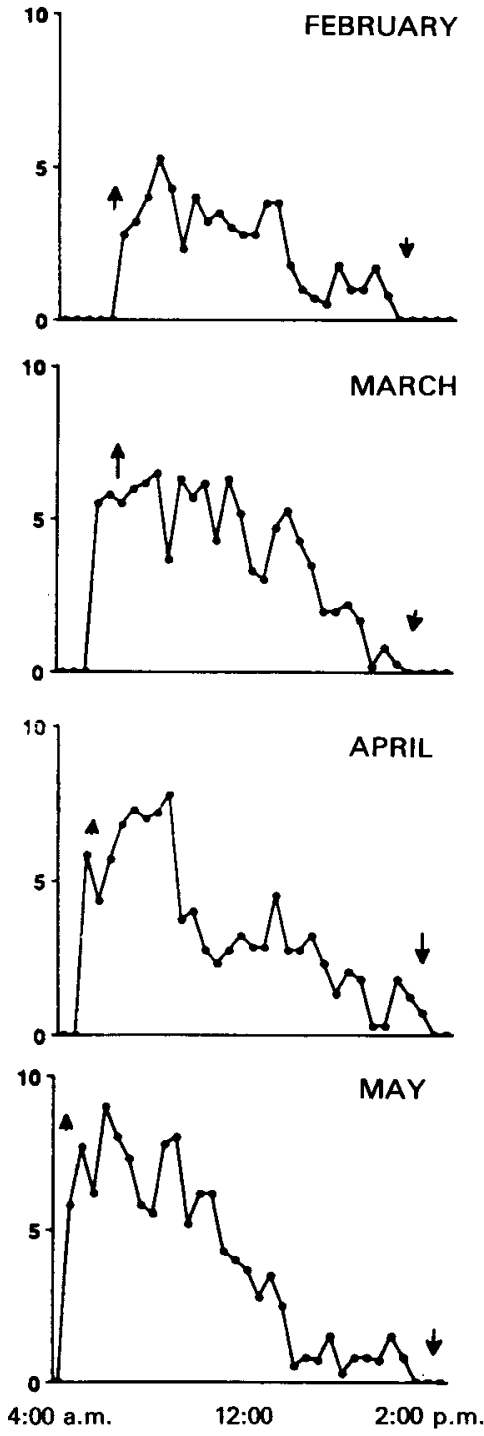
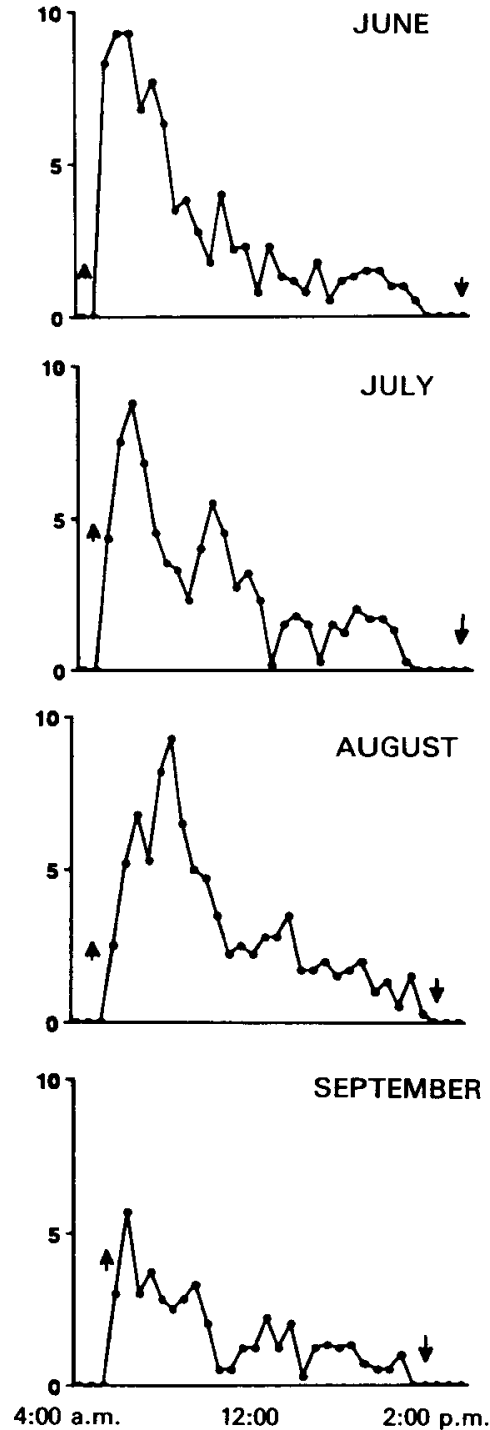

TIME OF DAY

Figure 1. Group mean number of locomotor movements of captive European Starlings as a function of daytime, averaged across 2 days of observation for each month of the year. Each data point represents the mean of three 10-min observation periods. Sunrise and sunset are indicated by the upward and downward deflected arrows, respectively. 


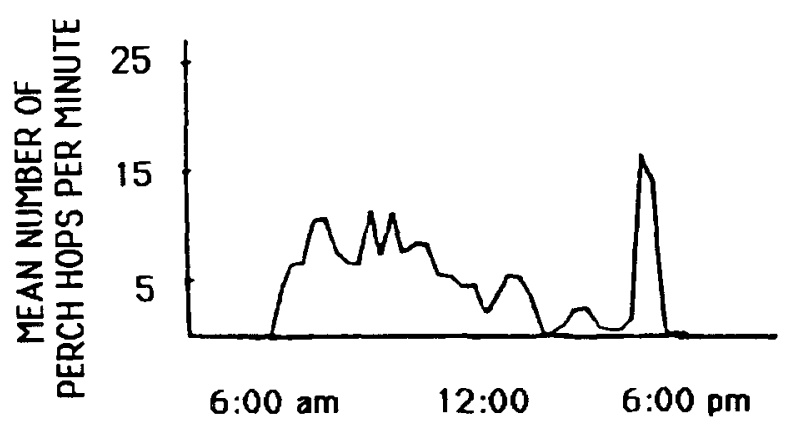

TIME OF DAY

Figure 2. Group mean number of perch hops of captive American Robins as a function of daytime, averaged across 2 days of observation for October, which is representative of all months. (From Eiserer, 1979.)

of the year. Individual data were consistent with the group data in this regard; no bird reliably generated an increase in activity at dusk during any month. What changed most from month to month, however, was the relative degree of activity during the early morning hours. During spring and summer (April through August), the starlings were extremely active in the morning, whereas during the late fall and winter (November through January), their level of morning activity was more subdued.

These impressions were confirmed by the results of a three-way ANOVA for repeated measures, which revealed a significant main effect for season $[F(3,15)=$ $7.232, p<.005]$, but not for time of day. Post-hoc comparisons further revealed that activity in fall and winter both differed significantly $(p<.05)$ from activity in both spring and summer. Differences in activity between fall and winter, and between spring and summer, did not differ significantly.

\section{DISCUSSION}

The daily activity of captive starlings parallels that of captive robins in several ways. In both cases there is an early morning period of moderately high activity, which gradually declines as the day progresses. By late morning and on throughout the afternoon, the two species engage in little or no activity. The early morning activity of both starlings and robins during the winter and fall is depressed, relative to the activity levels displayed during the late spring and early summer months. Unlike robins, however, captive starlings show no evidence of the brief burst of activity at dusk.

The fact that starlings, like robins, migrate during daylight hours (see Gruys-Casimir, cited in Feare, 1984) suggests that the common seasonal differences in morning activity of starlings and robins are attributable to migratory restlessness (Eiserer, 1979). Of course, starlings and robins migrate also in the fall, but the seasonal differences may be a behavioral correlate of the different metabolic adaptations associated with spring and fall migrations in some species (Berthold, 1975; King, Barker, \& Farner, 1963). It is likely that the seasonal differences in morning activity are related also in part to physiological and behavioral changes associated with breeding (see Dawson \& Goldsmith, 1982).

The daily progressive decline in activity during daylight hours by the captive starlings is consistent with the widespread pattern displayed by captive songbirds (Eyster, 1954; Ollason \& Slater, 1973; Palmgren, 1949; Smith et al., 1969). An eyeball inspection of the locomotor activity rhythms presented by Gwinner (1975) indicates that a similar pattern is generated by captive starlings kept under artificial lights with a 12:12-h light:dark cycle. There was nothing analogous to the burst of activity shown by robins at dusk in either this study or in Gwinner's (1975) data.

Indeed, the absence of roost-time restlessness in the starling was the most pertinent result for present purposes. In robins, roost-time restlessness may reflect a motivational conflict between remaining at their territories and departing for the roost (Eiserer, 1979). Because they are highly gregarious and not territorial in the broad sense, starlings may not need the extreme physiological readiness postulated for robins to induce flights to the communal roost site. Other factors, including social recruitment (Eiserer, 1984), possibly in conjunction with light intensity and time of sunset (Davis \& Lussenhop, 1970), may suffice to synchronize roost approach in this species. Such an influence of conspecifics on initiating roosting in starlings would not be surprising, given the evidence for conspecific influences on other classes of behavior such as foraging (Tinbergen \& Drent, 1980) and toxicant avoidance learning (Mason \& Reidinger, 1983).

If roost-time restlessness does in some sense reflect a conflict between roosting and territorial behaviors, why then does the phenomenon occur also without diminution throughout the nonbreeding portions of the year? In winter, individual robins are not territorial, but instead, like starlings, they forage in flocks during the daytime and travel to communal roosts. Nevertheless, captive robins show no decrement in the magnitude of roost-time restlessness during these months. Possibly a state of restlessness is necessary not only to induce robins to leave their territories during the breeding season but also to leave their foraging areas during the winter. Starlings, in contrast, might depend more upon social cues and changing light intensities during both the winter and the breeding season.

\section{REFERENCES}

BerThOLd. P. (1975). Migration: Control and metabolic physiology In D. S. Farner, J. R. King, \& K. C. Parks (Eds.), Avian biology (Vol. 5, pp. 77-128). New York: Academic Press.

BishOP, R. L. (Ed.) (1985). Observer's handbook. Toronto: University of Toronto Press.

BREWSTER, W. (1890). Summer robin roosts. Auk, 7, 360-373. 
DAvis, D. E. (1959). Territorial rank in Starlings. Animal Behaviour, 7, 214-221.

DAvis, G. J., \& LuSSENHOP, J. F. (1970). Roosting of starlings (Sturnus vulgaris): A function of light and time. Animal Behaviour, 18, 362-365.

Dawson, A., \& Goldsmith, R. (1982). Prolactin and gonadotrophin secretion in wild Starlings (Sturnus vulgaris) during the annual cycle and in relation to nesting incubation and rearing young. General Comparative Physiology, 48, 213-221.

EISERER, L. A. (1979). Roosttime restlessness in captive American Robins (Turdus migratorius). Animal Learning \& Behavior, 7, 406-412.

EISERER, L. A. (1980a). Ontogeny of roosttime restlessness in American Robins. Auk, 97, 196-196.

EISERER, L. A. (1980b). Seasonal changes in times of awakening, retiring, and roosttime restlessness in captive American Robins. Psychological Record, 30, 277-281.

EISERER, L. A. (1980c). Suppression of roosttime restlessness in incubating American Robins. Bird Behaviour, 2, 107-111.

EISERER, L. A. (1981). Contextual generality of roosttime restlessness in captive American robins (Turdus migratorius). Animal Learning \& Behavior, 9, 536-544.

Eiserer, L. A. (1984). Review: Communal roosting in birds. Bird Behaviour, 5, 61-80.

EYSTER, M. B. (1954). Quantitative measurement of the influence of photoperiod, temperature, and season on the activity of captive songbirds. Ecological Monographs, 24, 1-28.

Feare, C. J. (1984). The starling. New York: Oxford University Press. GWINNER, E. (1975). Circadian and circannual rhythms in birds. In D. S.
Farner, J. R. King, \& K. C. Parks (Eds.) Avian biology (Vol. 5, pp. 221-285). New York: Academic Press.

KING, J. R., BARKer, S., FARNer, D. S. (1963). A comparison of energy reserves during the autumnal and vernal migratory periods in the White-crowned Sparrow, Zonotrichia leucophrys gambelii. Ecology, 44, 513-521.

MAson, J. R., \& ReIDInger, R. F., JR. (1983). Conspecific individual recognition between starlings after toxicant-induced sickness. Animal Learning \& Behavior, 11, 332-336.

Ollason, J. C., \& Slater, P. J. B. (1973). Changes in the behavior of the male zebra finch during a 12-hr. day. Animal Behaviour, 21, 191-196.

PALmer, J. D. (1970). The biological clock of birds. In Field studies in natural history (pp. 55-65). New York: Van Nostrand Reinhold. Palmgren, P. (1949). On the diurnal rhythm of activity and rest in birds. Ibis, 91, 561-576.

Smith, R. W., Brown, I. L., \& Mewaldt, L. R. (1969). Annual activity patterns of caged non-migratory white-crowned sparrows. Wilson Bulletin, 81, 419-440.

Tinbergen, J. M., \& Drent, R. H. (1980). The Starling as a successful forager. In E. N. Wright, I. R. Inglis, \& C. J. Feare (Eds.), Bird problems in agriculture. Croydon, England: British Crop Portection Council.

Young, H. (1951). Territorial behavior in the eastern robin. Proceedings of the Linnaean Society of New York, 58, 1-37.

(Manuscript received January 11, 1988; revision accepted for publication August 23, 1988.) 